Published in final edited form as:

Brain Lang. 2008 July ; 106(1): 1-3.

\title{
The neuroscience of language
}

\author{
Steven L. Small, Ph.D., M.D.
}

This first issue of Volume 106 and the 421st issue since the journal's inception initiates both a new look and an updated editorial plan for Brain and Language. The mission of the journal remains the publication of the very best articles that relate human language to the organization, structure, and workings of the human brain. Nevertheless, there are some observable changes in emphasis and some practical differences in the mechanics of the review process. The discussions on the present and future state of Brain and Language were initiated several years ago and included a number of distinguished scholars from the various disciplines that comprise the majority of the authors and readers of the journal. At a meeting in Oxford last November, we made a decision to restructure and relaunch Brain and Language.

There are several goals for this restructuring. However, there is no intent to change the interdisciplinary focus, the methodological approaches of submitted research, or the topical emphasis on the interactions among brain, behavior, and language. Perhaps our most explicit goal is to make Brain and Language the premier venue for articles on the neurobiology of language. An increasing number of psychologists, neuroscientists, and linguists are now studying the neural basis of language, and an increasing number of journals that focus on cognitive and systems neuroscience are publishing high-impact language research. Further, the more general journals of neuroscience, psychology, and linguistics are publishing work on the brain and language, as are clinical journals in neurology, neurosurgery, psychiatry, and speech and language pathology, and basic journals in computer science, anthropology, mathematical biology, and sociology. The emerging field of social neuroscience is also capturing the interest of many researchers in brain and language. With such an enormous amount of competition for the best articles, we need to make sure that Brain and Language retains its special place in publishing articles that show deep interdisciplinary sophistication on the structure and processing of language and the biology of the human brain.

In January 1974, Professor Harry Whitaker of the Departments of Linguistics, Psychology, and Neurology of the University of Rochester wrote an editorial to mark the first issue of a new journal, Brain and Language. In this short article, he noted the both the "increasing number of scholars interested in brain and language" and the "development of new techniques and refinements of old ones which presage even more remarkable advances and insights in the future." In these comments, Whit was both accurate and remarkably prescient. By using keywords, "brain" and "language," and restricting the results to years 1974 and 2004, respectively, a quick search of both PubMed and Psycinfo finds just over 100 articles in the former year and just over 1000 in the latter, representing a full order of magnitude increase in 30 years. What has contributed most to this increase? The answer is most likely exactly what Whit presaged in his first editorial, namely, that technological development would lead to more

Publisher's Disclaimer: This is a PDF file of an unedited manuscript that has been accepted for publication. As a service to our customers we are providing this early version of the manuscript. The manuscript will undergo copyediting, typesetting, and review of the resulting proof before it is published in its final citable form. Please note that during the production process errors may be discovered which could affect the content, and all legal disclaimers that apply to the journal pertain.

This PDF receipt will only be used as the basis for generating PubMed Central (PMC) documents. PMC documents will be made available for review after conversion (approx. 2-3 weeks time). Any corrections that need to be made will be done at that time. No materials will be released to PMC without the approval of an author. Only the PMC documents will appear on PubMed Central -- this PDF Receipt will not appear on PubMed Central. 
and better ways to study the brain and language. This has happened to such a remarkable degree that no one could have predicted it just a short time ago. These changes have not only increased the volume of research in our field, but also altered its very nature, such that it is now possible to ask questions that could have barely been considered before.

For the past two centuries, scientists and clinicians interested in the biology of the human brain have had very few methods available to them. The most important of these, of course, was the behavioral investigation of individuals with brain lesions of various types, with the goal of relating the nature and distribution of injury to the nature and extent of behavioral disturbances. This method of "clinicopathological correlation" or "lesion analysis" was practiced widely, and led to the great advances of Pierre Paul Broca, Karl Wernicke, Jules Déjerine, Norman Geschwind, and the many others who have contributed to our most basic understanding of the brain and language. Many advances in the method have come about during its existence, from the development of high-resolution brain imaging, permitting the correlational approach to be done during life, rather than post-mortem, to the development a robust science of psychology, permitting more precise characterizations of behavior, to the revolution in linguistics of the last century, in which linguistic phenomena began to be characterized by formal theory. One of the byproducts of this approach was an emphasis on a direct mapping between functions (psychological or linguistic) and locations (brain regions).

Over the past 20 years, a number of new methods have emerged to study these structure/ function relationships in vastly novel ways, leading to both questions and elaborations of these localizational mappings. Many of these new methods do not depend on investigating a damaged neural system to make inferences about the state of the normal system, but instead enable investigation of the normal system directly (e.g., positron emission tomography, functional magnetic resonance imaging, magnetoencephalography, high field event-related encephalography, optical imaging). Other methods permit transient "lesions" (transcranial magnetic stimulation, transcranial direct current stimulation), so that behavior can be studied repeatedly in different states of the system. Combined with previous data from the clinicopathological correlation and/or new data collected from patients with injury using advanced versions of such lesion analysis, these methods are even more powerful. With the approaches now available, and with the increasing numbers of scientists making use of them, both individually and in combination, it has become not only possible, but commonplace, to ask question about the basic mechanisms of language in the brain.

About 15 years ago, I was asked to give a lecture on the "neurophysiology of language" for a group of first-year medical students at the University of Pittsburgh. After thinking about this for several weeks, I reported back to the course director that I would be happy to give a lecture on aphasia or on the brain anatomy for language, but not on physiology. The reason, I explained, was there was too little known about the topic to make an interesting or valuable lecture. Not unrelated to this observation was the general practice among academic departments, organizations, and journals in neuroscience to insist that scientifically robust research required non-human animal model systems and that physiology of the highest quality could simply not be performed with human subjects. Of course, this cut language out of the mix, and thus virtually no neuroscience or physiology department in the country contained researchers in human language, and neuroscience journals did not publish articles on language. This situation has changed virtually overnight. With functional imaging and high-density electrical and magnetic recording (and stimulation), a robust neuroscience of language is now possible. In examining four of the top neuroscience journals (Neuron, Nature Neuroscience, Journal of Neuroscience, and Annals of Neurology), one observes a steady increase in the number of articles published on human language, from 0 in 1974 (only two of these journals were in existence then), to between 30 and 40 per year now. This is paralleled by an increase in the numbers of published linguistic articles that reference the brain. Figure 1 shows this exponential 
growth in both biological and linguistic publications across a large number of journals. And it appears that this trend will only increase.

An important feature of Brain and Language has always been its strong interdisciplinary and theoretical emphasis, at the crossroads of neuroscience, linguistics, and experimental psychology. Whereas reviewers and readers of most journals in these fields generally have detailed knowledge of linguistic phenomena or theory, of psycholinguistic process or models, or of cellular or systems biology of the human brain, they seldom have knowledge of more than one at a time. We aim to maintain excellence in all three of these domains, i.e., to publish articles that study linguistic phenomena of known relevance, using process characterizations that have been tested experimentally, and with anatomical, physiological, and/or pharmacological sophistication. The stated goal for Brain and Language in 1974 was to publish articles from many different scientific and clinical disciplines, using diverse methods, but in which each paper was expected to address some aspect of human language and to relate it to brain function, and to do so with the highest standards of scholarship and insight. This remains the mission of Brain and Language.

Nevertheless, there remains a question of how Brain and Language differs from other journals that focus on aspects of cognition and the human brain. Certainly, the fundamental importance of language and linguistics to its mission remains the critical feature. But what differentiates Brain and Language from its close cousins in neuropsychology, cognitive neuroscience, and aphasiology? What is its special identity? In many discussions over the past 3 years, and finally in Oxford, this question was contemplated, discussed, and debated. Important to these discussions were the differences in scholarship and in academic process (e.g., recognition, promotion) among the disciplines of linguistics, neuroscience, and psychology, as well as in the related clinical disciplines, principally neurology and speech and language pathology. For example, in many countries, high impact factors are critical for promotion in neuroscience and neurology, but are barely relevant in linguistics, in which attestations of excellence by respected scholars play the more dominant role. In the neurosciences, rapid review and publication are considered critically important, whereas in linguistics and computer science, this is much less true. In the behavioral sciences, theoretical motivation is considered paramount; in the neurosciences, good hypotheses based on a history of empirical data are sufficient; and in the clinical sciences, utility and practicality can weigh heavily.

The result of this strategic planning process has led to the current relaunch of Brain and Language. What are the practical implications of this change? In terms of the types of articles solicited by Brain and Language, these are expected to come from the same sources as before, encompassing basic and clinical researchers from all disciplines who study the relationships between language and the human brain, and using the wide range of methods, both old and new, that are available for such study. On the other hand, these articles should be about the neuroscience of language, i.e., the neural mechanisms underlying the cognitive and linguistic processes used by the human brain to produce and to understand language. These articles should retain the multidisciplinary sophistication that has always characterized Brain and

Language, and should be of the very highest quality. Brain and Language remains true to its original mission as an interdisciplinary journal of language, behavior, and brain. Given the new possibility of understanding neural mechanisms in humans, Brain and Language will now also be the first journal explicitly devoted to the human neuroscience of language.

To implement this revised mission, a number of changes have been made to structure and functioning of the editorial process. First, a number of senior and highly respected scholars have agreed to serve as senior consulting editors of Brain and Language and are taking a vital advisory role during this time. Second, a number of accomplished scientists have agreed to serve as action editors of Brain and Language and will oversee an increasing number of 
submitted manuscripts. Third, the instructions for authors have been revised and now requests articles of three types: short communications, regular articles, and review articles. We will determine during the coming years whether to add book reviews, letters, and/or other types of short notes. Fourth, the review process has been streamlined, so that all articles now receive a pre-review by a senior consulting editor and/or by the editor in chief, with only a relatively small portion of submitted articles sent for full peer review. This will permit more efficient use of reviewers and help ensure that articles that are most appropriate for the journal receive the highest quality reviews. Finally, we will increase the number of special issues of Brain and Language, to address fundamental topics in the neuroscience of language. All of our readers are encouraged to consider topics of interest and to suggest them to members of the editorial board.

On behalf of the senior consulting editors and the editorial board of Brain and Language, I thank you all for your support over the past 34 years in submitting manuscripts, in reviewing the submissions of others, and in citing published articles from Brain and Language. We are all hopeful that the changes being put into place with this issue will lead to a revitalized journal and a strong competitor for the very best manuscripts on the neuroscience of human language. If any members of our community would like to make suggestions, offer criticism, or discuss editorial policies or procedures, please do not hesitate to contact me directly or any other member of the editorial board. 


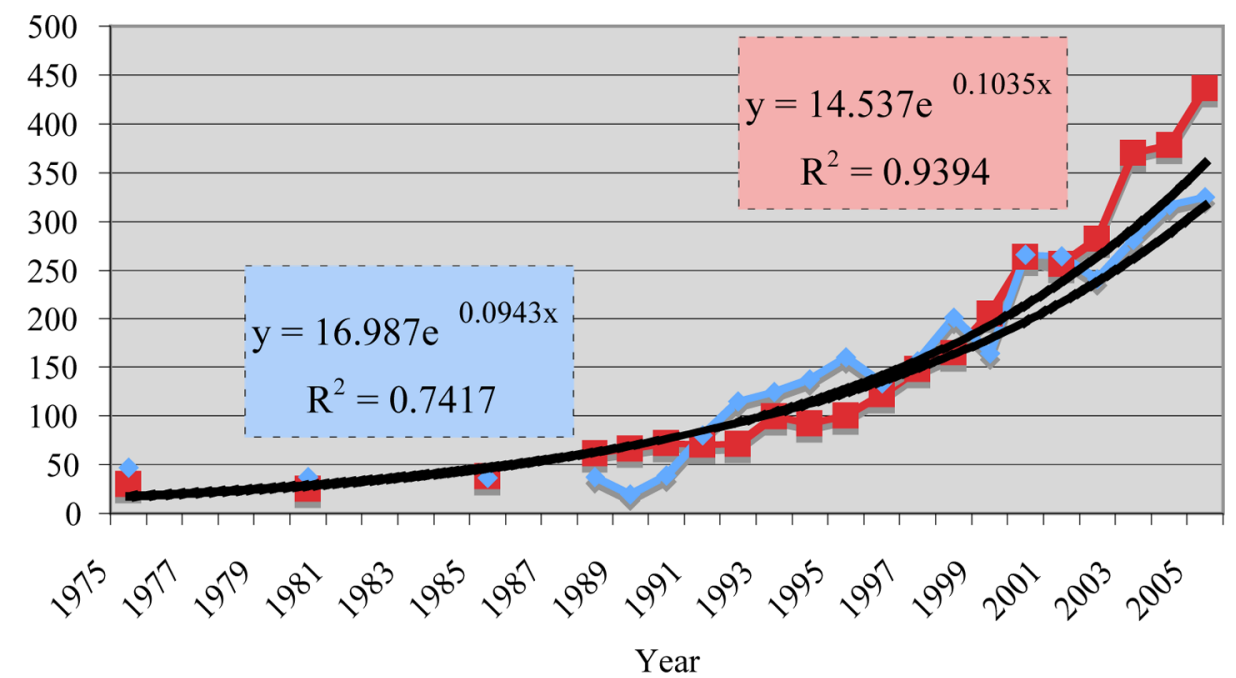

Fig. 1.

Number of articles on PubMed that contain the word "brain" in the title or abstract and list keyword "language" ( - red squares), and number of articles in CSA Linguistics and Language Behavior Abstracts that list descriptor "brain” ( • blue circles). Curves demonstrate exponential models with equations and $R^{2}$ values shown for each. 